\title{
A CONSTRUÇÃO DO MAPA DA JUVENTUDE DE SÃO PAULO*
}

\author{
AYLENE BOUSQUAT \\ AMÉLIA COHN
}

O Mapa da Juventude da Cidade de São Paulo foi elaborado a partir de uma metodologia que buscou articular a dimensão da construção do espaço urbano da metrópole paulista com questões específicas da(s) juventude(s) paulistana(s). O objetivo da pesquisa consistia em mapear a presença de distintas formas de agrupamentos juvenis e traçar o(s) perfil(s) desses jovens.

Um dos principais desafios enfrentados nessa construção metodológica foi a necessidade de se harmonizar tempos e ritmos notadamente diferentes: aqueles exigidos pela política, mais propriamente pelo Executivo, com aqueles exigidos pela pesquisa, quando pautada pelas exigências dos procedimentos científicos.

Nesse sentido, a elaboração do Mapa da Juventude da Cidade de São Paulo no curto período de 5 meses só foi possível por se contar com o suporte de pesquisas anteriormente realizadas sobre diferenciais intraurbanos, mas fundamentalmente por se optar por uma metodologia que parte da questão urbana, de como a construção do espaço nesta complexa metrópole brasileira é marcada por profundas desigualdades socioespaciais.

A incorporação da dimensão espacial da exclusão social apresentava-se como possibilidade metodológica para se apreender algumas das características da(s) juventude(s) paulistana(s). Garantia-se com isso a visibilidade da grande maioria dos jovens paulistanos, e não apenas

\footnotetext{
* Os resultados aqui apresentados foram extraídos do "Mapa da Juventude da Cidade de São Paulo", realizado pelo Cedec por solicitação da Coordenadoria da Juventude da Prefeitura Municipal de São Paulo (PMSP). A pesquisa foi coordenada pelas autoras deste artigo; os antropólogos Eunice Nakamura, Gabriel Coutinho Barbosa e José Ronaldo Trindade foram responsáveis pela coordenação de campo.
} 
daqueles que percorrem os circuitos conhecidos da cidade, vale dizer, os circuitos dos incluídos. Esta era uma condição fundamental para que o Mapa pudesse efetivamente fornecer subsídios para a elaboração de políticas públicas promotoras da eqüidade. Afinal, não se estava diante de uma juventude abstrata, e sim de aproximadamente dois milhões de jovens vivendo e construindo seu futuro e suas expectativas na maior cidade brasileira, detentora de status de metrópole global. Metrópole esta que, no entanto, da mesma forma que as demais metrópoles de países periféricos e semiperiféricos, insere-se no circuito mundial da economia articulada a um modelo concentrador de riquezas e marcado por forte exclusão socioespacial (Borja e Castells,1998). Daí o objetivo de se buscar identificar algumas das principais características da inserção dos jovens nessa metrópole.

Embora as discussões sobre a dimensão espacial da desigualdade social não sejam recentes, tendo sido contempladas desde os estudos pioneiros da Escola de Chicago, é somente a partir da segunda metade do século XX que a literatura especializada, em particular nos campos das Ciências Sociais e da Geografia, vem absorvendo de modo mais significativo a perspectiva de se assumir as relações sociais e espaciais como homólogas e dialeticamente inseparáveis (Lefèbvre, 1976, 1991, 1995; Soja, 1989). No nosso caso específico, Torres (2003: 4) aponta que enquanto internacionalmente se verifica uma "forte ênfase na questão da separação entre grupos sociais e da homogeneidade social das várias partes da cidade, estruturada especialmente pela etnia e pela raça", a literatura brasileira "tem se concentrado principalmente na existência de desigualdades e injustiças na distribuição de renda e de serviços públicos mais do que na separação de grupos sociais".

Foi com o propósito de se identificar homogeneidades e segregações dos jovens no espaço urbano paulistano que a elaboração do Mapa da Juventude associou às questões das distintas inserções desses jovens no mundo do trabalho e da escola aquelas relacionadas aos seus hábitos e práticas, incluindo o lazer e o uso da cidade, discriminadas segundo as distintas regiões da cidade.

Apresenta-se a seguir a) os principais traços que marcaram a construção urbana da metrópole paulista; b) o detalhamento da metodologia, com especial atenção para a construção das chamadas Zonas Homogêneas Juvenis, que permitiram que se traçasse um Perfil do Jovem Paulistano; e c) alguns resultados encontrados, evidenciando assim as potencialidades da metodologia utilizada na pesquisa. 


\section{O PADRÃO DE EXCLUSÃO SOCIOESPACIAL}

Na segunda metade do século XX, São Paulo constitui-se como a metrópole brasileira por excelência, inicialmente se consolidando como metrópole industrial e, a partir da década de oitenta, após uma modificação radical de sua essência, como metrópole transacional. Dado que o entendimento desse processo se constitui no principal arcabouço da metodologia elaborada para a execução do Mapa da Juventude, serão apresentadas algumas características desses dois períodos, tomando como referência central os processos socioespaciais de exclusão.

Até a década de setenta, a concentração de atividades econômicas, particularmente industriais, pode ser considerada o eixo organizador da cidade de São Paulo. Esta lógica resulta num modelo de ocupação urbana bastante polarizado e desigual, em que o crescimento demográfico, a migração para as metrópoles, a disponibilidade de significativo exército industrial de reserva constituem alguns dos elementos que marcam esse período. Notadamente em São Paulo, esse modelo de ocupação urbana caracteriza-se pelo fenômeno da "periferização", com o início de um ciclo de loteamentos urbanos, na maioria das vezes clandestinos, aliados à "alternativa" da autoconstrução, à valorização do solo e à especulação imobiliária em terrenos cada vez mais distantes do centro (Bógus e Wanderley, 1992; Kowarick, 1979).

Diversos estudos realizados entre os anos 1970 e 1980 consolidam a noção de "periferia", caracterizada então pelas péssimas condições de vida de seus moradores e pela ausência de intervenções estatais - exceto pela execução dos grandes conjuntos habitacionais (Brant, 1989; Jacobi, 1989; Bonduki e Rolnik, 1982; Santos, 1993a). Ribeiro e Lago (1992: 161), por sua vez, definem "periferização" como um fenômeno que "não quer dar conta apenas de um locus, mas de um processo de segregação e diferenciação social no espaço que tem causas econômicas, políticas e culturais" e no qual "consolida-se a imagem de espaços socialmente homogêneos".

Segundo Marques e Bichir (2001:10), "se havia consenso em relação às péssimas condições de vida nas periferias" na literatura sociológica e urbana da década de setenta e início de oitenta, os "processos produtores do espaço eram objeto de descrições diversificadas e nem sempre compatíveis". Os autores apontam que, naquele período, o conjunto da literatura nacional na área mobilizou mecanismos estruturais e/ou de natureza econômica para explicar a conformação da cidade e as políticas 
estatais, seja ligando-as ao modo de produção, em sua versão influenciada pelo marxismo estruturalista francês, seja associando-as ao comportamento econômico de agentes sociais ${ }^{1}$.

Em suma, a consolidação de São Paulo como a metrópole industrial brasileira nas décadas de sessenta e setenta se assenta, ao mesmo tempo que cria, uma cidade marcada por forte desigualdade espacial, cujo modelo de crescimento é fortemente dual (centro versus periferia). A partir dos anos oitenta, no entanto, uma nova lógica econômica se impõe, com aumento progressivo do peso dos setores terciário e quaternário na economia. Neste período, São Paulo consolida-se como uma metrópole transacional. Se a fórmula de manutenção do poder da metrópole industrial consistia até então em crescer sem parar - aumentando sua área de influência contígua, incrementando o número de plantas industriais e de serviços, atraindo populações migrantes -, o mesmo não ocorre na metrópole transacional. Neste caso, como a informação é peça-chave desse processo, a metrópole transacional não precisa necessariamente agregar todos os elementos no interior de seu território, e mesmo assim torna-se possível manter o comando e a direção política e econômica do país.

A incorporação de novas tecnologias, com ênfase na circulação de informações; o fenômeno da "involução metropolitana", caracterizado pelo menor crescimento da cidade-sede em comparação com o dos demais municípios que compõem a região metropolitana; a especialização nos setores terciário e quaternário da economia; a diminuição relativa do peso industrial, associada à mudança nas características das plantas industriais que tendem a se tornar menores, automatizadas e não poluentes; o aumento da economia e do emprego informal, bem como das desigualdades e da pobreza são alguns dos elementos dessa transformação radical (Santos, 1994). E o modelo espacial daí decorrente tende a ser menos polarizador do que o primeiro, causando reflexos importantes não só no uso do solo e na divisão espacial do trabalho, como na vida de seus moradores. Esse novo padrão aumenta o dinamismo urbano e possibilita a criação de "subcentros", mas não transita para uma ruptura com padrões espaciais de desigualdade consolidados durante o período anterior de industrialização da capital paulista (Mello, 1998). Ressalte-se que, da mesma forma que outras metrópoles transacionais de países capitalistas periféricos, o processo de conformação da metrópole transacional paulista é marcado pela

1 Os estudos de Kowarick (1979) e Bonduki e Rolnik (1982) representariam a primeira influência, enquanto os de Santos, C. (1982) a segunda. 
"intensificação e a renovação dos processos sociais de exclusão... Em outros termos, as novas feições na paisagem e a intensificação da exclusão social estão presentes nas metrópoles contemporâneas", o que aumenta a importância da dimensão espacial da exclusão social (Lencioni,1998:40).

Dessa forma, no processo de consolidação da metrópole transacional, a dimensão espacial da exclusão ganha novos contornos, tornandose mais complexa. O modelo dual (centro versus periferia), que contrastava de um lado o centro rico e de outro periferias pobres e com escassez de serviços públicos, não se revela mais suficiente como modelo explicativo da construção urbana da metrópole paulista. Evidências empíricas apontam para a disseminação da pobreza por toda a cidade, em pequenos espaços mais próximos do centro; para um aumento de investimentos públicos na direção das periferias, além da existência de um gradiente de crescimento de condomínios fechados com alto poder aquisitivo na direção do vetor de expansão oeste da cidade, até há bem pouco tempo ocupado apenas por populações com baixo poder aquisitivo (Torres et alii, 2003).

A inserção da juventude nessa complexa metrópole por si só é uma questão instigante; agregue-se a isso o fato de que Torres et alii (2003), ao realizarem um estudo sobre padrões de segregação socioespacial em São Paulo, constataram que a existência de alta proporção de adolescentes numa determinada região correlaciona-se estreitamente à existência de pobreza nessa mesma região, o que de certa forma aponta para uma especificidade da realidade paulistana, pois em outras cidades essa relação se dá com a presença de crianças e não com a de adolescentes.

\section{AS ETAPAS DO MAPA DA JUVENTUDE DE SÃO PAULO}

Para a execução do Mapa, foi realizado um longo e sinuoso percurso que articulou distintos componentes: um Inquérito Domiciliar, um survey do Bolsa-Trabalho, um Levantamento de Equipamentos e Espaços de Lazer e um Cadastramento dos Grupos.

O Inquérito Domiciliar foi realizado a partir das chamadas Zonas Homogêneas, constituídas tendo como base a dimensão espacial da exclusão social dos jovens paulistanos, garantindo-se assim a visibilidade de jovens com diferentes inserções sociais.

O survey do Bolsa-Trabalho caminhou na mesma direção, aportando mais informações sobre jovens moradores das áreas com maior exclusão social. O Programa Bolsa-Trabalho foi criado pela Secretaria de 
Desenvolvimento, Trabalho e Solidariedade da Prefeitura Municipal de São Paulo (SDTS/PMSP) em 2001, sendo destinado a jovens desempregados com idade entre 16 e 20 anos, pertencentes a famílias de baixa renda. Dessa forma, a incorporação desses bolsistas como informantes privilegiados configurou-se como recurso adicional para garantir a visibilidade no Mapa daqueles jovens das regiões menos incluídas nos circuitos comerciais. O survey alcançou 1.400 bolsistas.

O Levantamento de Equipamentos e Espaços de Lazer foi realizado com dois objetivos: disponibilizar, em uma única fonte, as informações - no geral bastante dispersas - sobre esses equipamentos; e fornecer elementos para se traçar os circuitos realizados pelos jovens no conjunto da cidade, tomando-se como referência os equipamentos existentes.

Por fim, o Cadastramento dos Grupos de Jovens Paulistanos. Foram cadastrados 1.609 grupos, somando 303.592 participantes. Embora não tenham sido objeto dessa análise, o que se buscava nesse caso era conhecer as principais motivações que levam os jovens a se organizar em grupos, o grau de formalização desses grupos e as atividades que realizam. Dois aspectos, no entanto, foram privilegiados na análise desses dados: as práticas de lazer e a participação em grupos, ambos entendidos como estratégias que expressam mais profundamente o significado de ser jovem nessa metrópole. De fato, o Cadastramento dos Grupos revelou uma juventude atuante, distante da imagem de juventude "alienada". Jovens que se reúnem pelos mais distintos motivos: para desenvolver manifestações artísticas, esportivas, religiosas, políticas e de ação social. Jovens que se reúnem para refletir, criticar, discutir problemas sociais e políticos, atuar junto à comunidade.

A articulação destes quatro componentes é a base da elaboração do Mapa da Juventude; ela aportou novos elementos que contribuem para que se desenhe um perfil da(s) juventude(s) paulistana(s).

\section{AS ZONAS HOMOGÊNEAS E O INQUÉRITO DOMICILIAR}

A realização do Inquérito Domiciliar acabou sendo uma das etapas mais complexas e ricas na elaboração do Mapa. Mais do que simplesmente traçar um perfil das atividades de diversão realizadas e/ou desejadas por esses jovens, o inquérito desenhou o perfil social, econômico e cultural da juventude paulistana .

Para sua realização, os 96 Distritos Administrativos do município foram divididos em 5 grupos, denominados de Zonas Homogêneas 
(ZH), cada uma delas agrupando um conjunto de distritos com perfis semelhantes do ponto de vista da inserção do jovem naquela realidade. A identificação dos distintos perfis dos distritos se baseou na elaboração de um indicador composto, denominado Indicador Composto Juvenil, construído a partir das seguintes variáveis:

- Percentual da População Jovem do Distrito.

- Taxa Anual de Crescimento Populacional do Distrito entre 1991 e 2000.

- Percentual de Mães Adolescentes no Total de Nascidos Vivos.

- Coeficiente de Mortalidade por Homicídios na Faixa Etária de 15 a 24.

- Percentual de Jovens que Não Freqüentam Escola.

- Coeficiente de Viagens por Motivo de Lazer, por Distrito.

- Índice de Mobilidade da População de 15 a 24 anos.

- Valor do Rendimento Médio Mensal Familiar.

Essas variáveis foram selecionadas a partir dos resultados de pesquisas anteriormente realizadas pela Fundação Seade (Índice de Vulnerabilidade Juvenil), pela PUC/Cedec (Mapa da Exclusão Social) e pelo Cedec (Mapas de Risco da Violência). Cada variável selecionada foi identificada e/ou calculada para todos os distritos da cidade de São Paulo. Foi então criado um ranking para cada variável, onde os distritos eram classificados do melhor para o pior resultado obtido naquela variável específica. Em seguida, cada distrito recebeu uma nota, sendo que o distrito com o melhor indicador recebeu nota 1 , e o pior, nota 0 . A partir da definição do melhor e do pior resultado, foram calculadas proporcionalmente notas para os outros distritos. Ao final, foram somadas as notas obtidas por cada distrito em todas as variáveis pesquisadas, sendo apurada uma média ponderada. Esta média foi denominada de Indicador Composto Juvenil (ICJ). ATabela 1 apresenta o ranking encontrado para cada distrito da capital.

A partir da definição do ICJ, os distritos foram agrupados em 5 conglomerados (as Zonas Homogêneas), sendo que a ZH1 é aquela que reúne os distritos com as melhores condições para os jovens, e a ZH5, os piores (Mapa 1).

Em seguida, foi delineada uma amostra probabilística por conglomerado, tomando-se como unidade de amostragem primária as cinco Zonas Homogêneas definidas. Em cada uma delas foram sorteados 70 setores censitários, com probabilidade associada ao número de setores de cada distrito. Assim, os distritos que apresentavam um número maior de setores tinham maior probabilidade de terem esses setores sorteados. 
Tabela 1: Indicador Composto Juvenil - Distritos Administrativos, Município de São Paulo, 2003

\begin{tabular}{|c|c|c|c|}
\hline Distrito & Indicador & Distrito & Indicador \\
\hline Jardim Paulista & 0,78 & Limão & 0,41 \\
\hline Moema & 0,77 & Aricanduva & 0,41 \\
\hline Pinheiros & 0,76 & Jaguaré & 0,39 \\
\hline Itaim Bibi & 0,74 & Pirituba & 0,39 \\
\hline Consolação & 0,69 & Jabaquara & 0,39 \\
\hline Alto Pinheiros & 0,67 & Ponte Rasa & 0,38 \\
\hline Lapa & 0,67 & Rio Pequeno & 0,38 \\
\hline Perdizes & 0,66 & Cangaíba & 0,36 \\
\hline Vila Mariana & 0,65 & Sacomã & 0,36 \\
\hline Santo Amaro & 0,65 & Artur Alvim & 0,36 \\
\hline Tatuapé & 0,64 & Tremembé & 0,35 \\
\hline Moóca & 0,64 & Vila Maria & 0,35 \\
\hline Saúde & 0,61 & Vila Andrade & 0,33 \\
\hline Barra Funda & 0,6 & Ermelino Matarazzo & 0,33 \\
\hline Sé & 0,6 & Cidade Líder & 0,33 \\
\hline Campo Belo & 0,59 & Vila Medeiros & 0,33 \\
\hline Santa Cecília & 0,58 & Itaquera & 0,32 \\
\hline Morumbi & 0,58 & São Mateus & 0,32 \\
\hline Butantã & 0,57 & São Miguel Paulista & 0,32 \\
\hline Bela Vista & 0,57 & Raposo Tavares & 0,31 \\
\hline República & 0,55 & Jaçanã & 0,31 \\
\hline Vila Guilherme & 0,55 & Vila Jacuí & 0,3 \\
\hline Água Rasa & 0,55 & Cidade Dutra & 0,3 \\
\hline Santana & 0,55 & Campo Limpo & 0,29 \\
\hline Vila Leopoldina & 0,55 & Parque do Carmo & 0,29 \\
\hline Liberdade & 0,53 & José Bonifácio & 0,29 \\
\hline Belém & 0,52 & Jaraguá & 0,28 \\
\hline Pari & 0,52 & Vila Curuçá & 0,28 \\
\hline Carrão & 0,52 & Sapopemba & 0,28 \\
\hline Tucuruvi & 0,51 & Perus & 0,26 \\
\hline Campo Grande & 0,51 & Jardim São Luís & 0,25 \\
\hline Ipiranga & 0,51 & Marsilac & 0,25 \\
\hline Cambuci & 0,51 & Anhangüera & 0,25 \\
\hline Mandaqui & 0,5 & Itaim Paulista & 0,25 \\
\hline Penha & 0,5 & São Rafael & 0,25 \\
\hline Cursino & 0,5 & Cachoeirinha & 0,25 \\
\hline Brás & 0,49 & Guaianazes & 0,25 \\
\hline Vila Matilde & 0,48 & Lajeado & 0,23 \\
\hline Bom Retiro & 0,48 & Cidade Ademar & 0,23 \\
\hline Jaguara & 0,47 & Jardim Helena & 0,22 \\
\hline Vila Prudente & 0,47 & Capão Redondo & 0,22 \\
\hline Vila Sônia & 0,46 & Pedreira & 0,21 \\
\hline Vila Formosa & 0,46 & Brasilândia & 0,21 \\
\hline Socorro & 0,46 & Iguatemi & 0,2 \\
\hline Freguesia do Ó & 0,45 & Cidade Tiradentes & 0,18 \\
\hline Casa Verde & 0,45 & Jardim ngela & 0,18 \\
\hline São Lucas & 0,44 & Grajaú & 0,14 \\
\hline São Domingos & 0,42 & Parelheiros & 0,13 \\
\hline
\end{tabular}




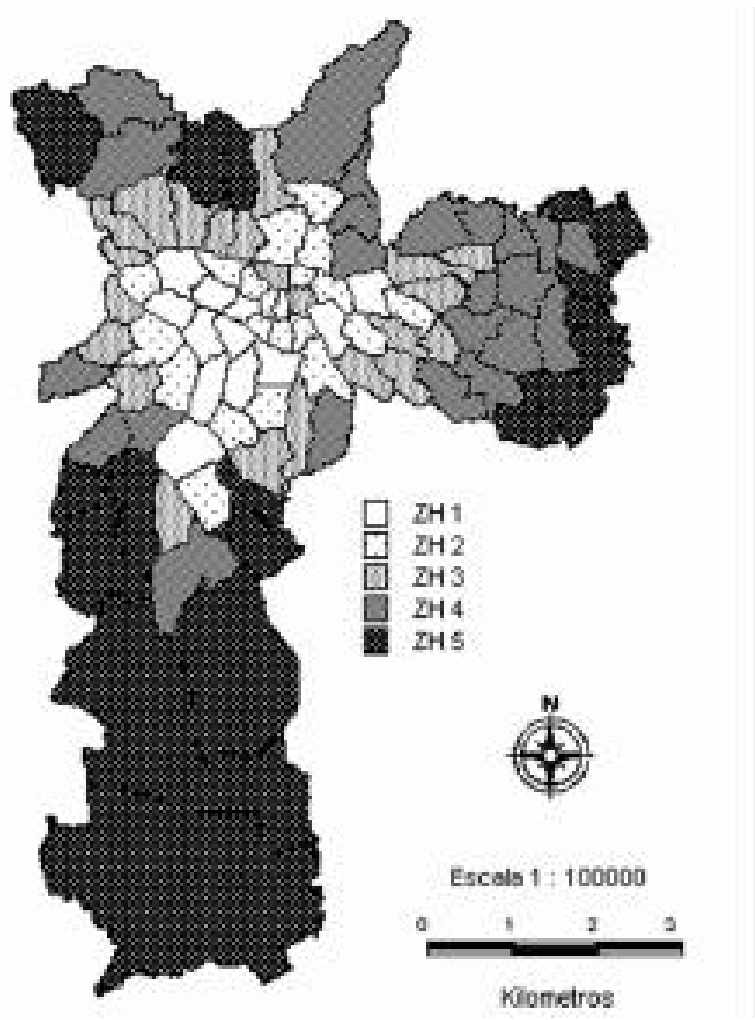

Mapa 1: Zonas Homogêneas Juvenis - Mapa da Juventude da Cidade de São Paulo, 2003.

Após esse procedimento, foram sorteadas, por meio dos mapas dos setores censitários, as quadras a serem visitadas. Nessa etapa, foram incluídas somente quadras reconhecidamente residenciais, sendo excluídas todas as demais, inclusive aquelas pertencentes a áreas industriais, comerciais etc.

Em cada unidade de amostragem secundária (setor censitário) foram selecionadas aleatoriamente duas quadras residenciais, sendo a primeira utilizada para a coleta dos dados e a segunda considerada como unidade de substituição para casos onde não foi possível a abordagem da quadra anterior. Em cada quadra foram visitadas 15 unidades consideradas como domicílios com o objetivo de identificar a presença de jovens na faixa etária de interesse ( 15 a 24 anos). 
O tamanho da amostra foi determinado considerando-se a proporção estimada do evento de interesse igual a 50\%, margem de erro de 5\% e nível de significância das estimativas a serem obtidas correspondente a 95\%. Ao valor do tamanho da amostra foram aplicados uma taxa de perda de $9,4 \%$ e um efeito de desenho da amostra igual a 2. Os jovens identificados responderam a um questionário - aplicado por entrevistador previamente treinado organizado pelos eixos temáticos elencados abaixo:

- Caracterização do jovem (idade, cor, sexo, local de moradia, naturalidade).

- Situação familiar (com quem mora, estado civil, filhos).

- Escolaridade (atual ou último ano em curso, tipo de estabelecimento de ensino e horário de estudo).

- Inserção no mercado de trabalho (tipo de renda, em qual setor trabalha, inserção no mercado formal ).

- Atividades de lazer (tipo e local das principais atividades de lazer, preferência musical, uso de equipamentos públicos).

- Acesso à internet.

- Participação em grupos.

- Expectativas (de atividades e de equipamentos em seu bairro).

- Informações sobre AIDS.

Foram visitados 5.250 domicílios e aplicados 2.259 questionários, estratificados pelas cinco Zonas Homogêneas Juvenis da cidade de São Paulo (Tabela 2).

\section{ALGUNS RESULTADOS}

A metodologia desenvolvida revelou-se apropriada para o objetivo de se evidenciar diferenças e desigualdades importantes entre os jo-

Tabela 2: Distribuição dos entrevistados e do $\mathrm{n}^{\circ}$ de jovens residentes por Zona Homogênea - Mapa da Juventude de São Paulo, 2003.

\begin{tabular}{ccccc}
\hline ZH & $\begin{array}{c}\text { Número de } \\
\text { entrevistados }\end{array}$ & $\begin{array}{c}\text { Percentual de } \\
\text { jovens no } \\
\text { inquérito } \\
\text { Domiciliar }\end{array}$ & $\begin{array}{c}\text { Número de } \\
\text { habitantes } \\
(15-24 \text { anos })\end{array}$ & $\begin{array}{c}\text { Percentual de } \\
\text { jovens } \\
\text { residentes }\end{array}$ \\
\hline 1 & 156 & 6,90 & 129.793 & 7,07 \\
2 & 261 & 11,55 & 217.262 & 10,91 \\
3 & 550 & 24,34 & 457.849 & 19,12 \\
4 & 586 & 25,94 & 487.945 & 31,98 \\
5 & 706 & 31,25 & 587.829 & 30,89 \\
\hline
\end{tabular}


vens das diferentes regiões da cidade. Para exemplificar os distintos padrões de inserção dos jovens pelas cinco Zonas Homogêneas, são apresentados a seguir os resultados da distribuição dos jovens por cor autoreferida, por exclusão digital, por número de filhos, por inserção no mercado formal de trabalho e por estilos musicais preferidos.

Antes disso, no entanto, cabe um breve comentário a respeito da opção metodológica utilizada para a definição da cor, que se baseou fundamentalmente no método empregado no Censo pelo IBGE. Este método consiste na definição auto-referida da cor do entrevistado, ou seja: diante de um conjunto de alternativas apresentadas, é ele quem define sua cor. Embora seja generalizado o entendimento de que "manter a forma de classificar do IBGE, sempre fraseada com a palavra 'cor', faz-se necessário para manter-se a comparabilidade entre diversas fontes de dados", Guimarães (2003: 98)2 registra a necessidade de se utilizar conceitos de cor que sejam reconhecidos pelos grupos investigados. Nesse sentido, ele aponta que embora no Brasil "raça continue a não ser um conceito nativo", diferentemente de países como os Estados Unidos, onde "raça é um conceito nativo classificatório, central para a sociedade", existem aqui diversos movimentos negros para os quais esse conceito assume status fundamental. Como o Mapa da Juventude se propunha a cadastrar também os grupos de jovens ligados a esses movimentos, optou-se por acrescentar o item "negro" ao conjunto de alternativas apresentadas.

Quanto aos resultados encontrados, observa-se que a maioria dos entrevistados identificou-se como de cor "branca" (51,9\%), superando a soma de todas as demais alternativas. No entanto, quando comparada sua distribuição segundo ZH (Tabela 3), nota-se aumento expressivo no per-

Tabela 3: Distribuição dos jovens por cor auto-referida - Zonas Homogêneas - Mapa da Juventude da Cidade de São Paulo, 2003.

\begin{tabular}{lcrrrrr}
\hline \multicolumn{7}{c}{ Jovens entrevistados (\%) } \\
\hline Cor & Município & ZH1 & ZH2 & ZH3 & ZH4 & ZH5 \\
\hline Branca & 51,9 & 85,9 & 69,3 & 54,2 & 51,0 & 37,0 \\
Preta/negra & 14,8 & 3,8 & 9,2 & 16,9 & 14,5 & 18,0 \\
Parda & 28,6 & 7,7 & 16,9 & 24,2 & 31,6 & 38,7 \\
Amarela & 2,1 & 2,6 & 3,1 & 2,0 & 1,5 & 2,3 \\
Indígena & 2,3 & - & 1,5 & 2,4 & 1,4 & 3,8 \\
\hline
\end{tabular}

2 Nesse artigo , Guimarães trata não só da operacionalização do conceito de cor, mas também dos conceitos de raça e etnia. Sobre as metodologias utilizadas para definição de raça/cor/etnia em recenseamentos de diversos países ao longo dos anos, ver Petruccelli (2002). 
centual de entrevistados que se classificam como "pretos/negros" e "pardos" nas Zonas com maior exclusão (3, 4 e 5); na ZH 5 - a de pior posição no ranking - o conjunto de negros/pretos e pardos ultrapassa o de brancos.

De certa forma, esses dados reafirmam a ênfase que vem sendo dada na literatura internacional sobre os padrões socioespaciais de segregação com constituição de espaços homogêneos estruturados sobretudo segundo raça e etnia, configurando-se como verdadeiros guetos nas metrópoles, mesmo no caso dos países centrais (Logan, 2000; Marcuse, 1996; Fainstein,1992).

Quanto à distribuição do número de filhos por jovens, ela adquire importância dado que "a gravidez na adolescência traz sérios problemas para programas de Saúde Pública, para projetos educacionais, para a vida familiar, e para o desenvolvimento pessoal, social e profissional da jovem gestante, como vem sendo reconhecido pela literatura" (Dias e Gomes, 2000). Essas questões se agravam ainda mais quando são examinadas as relações entre gravidez precoce, educação e pobreza, uma vez que adolescentes das faixas de renda familiar menores, de até ? do salário mínimo per capita, têm chance quase nula de completarem o segundo grau após o nascimento de um filho. Henriques e col. (1989) identificaram que apenas $2 \%$ das adolescentes com essas características prosseguiram sua educação após o nascimento do filho. A não-continuidade dos estudos significará menor qualificação e portanto menores chances de competir num mercado de trabalho cada vez mais exigente e com menos ofertas, além da submissão ao trabalho informal e mal-remunerado (Oliveira, 1998).

A análise do número médio de filhos por jovem também é ilustrativa das diferenças entre as distintas regiões da cidade (Tabela 4): dos jovens entrevistados, $13,9 \%$ já têm filhos; dentre estes, o número médio de filhos é de 1,42. Constatou-se uma enorme diferenciação entre as distintas ZHs, observando-se mais uma vez características marcantes naquelas situadas nos extremos: na ZH1, 97,4\% dos jovens não têm filhos, contrastando com os 17,8\% da ZH5 que declararam ter filhos.

Tabela 4: Distribuição dos entrevistados com filhos por Zona Homogênea - Mapa da Juventude da Cidade de São Paulo, 2003.

\begin{tabular}{lcccccc}
\hline & $\begin{array}{c}\mathrm{ZH} 1 \\
\%\end{array}$ & $\begin{array}{c}\mathrm{ZH} 2 \\
\%\end{array}$ & $\begin{array}{c}\mathrm{ZH} 3 \\
\%\end{array}$ & $\begin{array}{c}\mathrm{ZH} 4 \\
\%\end{array}$ & $\begin{array}{c}\mathrm{ZH} 5 \\
\%\end{array}$ & $\begin{array}{c}\text { Total } \\
\%\end{array}$ \\
\hline Não & 97,4 & 89,3 & 87,6 & 84,5 & 82,2 & 86 \\
Sim & 2,6 & 10,7 & 12 & 15,5 & 17,8 & 13,9 \\
Ignorado & - & - & 0,4 & - & - & 0,1 \\
\hline
\end{tabular}


Já no que diz respeito à inserção dos jovens no mercado de trabalho, observa-se que 33,2\% dos entrevistados trabalham, sendo que o maior percentual é encontrado na ZH1 (43,6\%), que apresenta também os melhores indicadores (Tabela 5). Esse aparente paradoxo pode estar indicando uma mudança do perfil do mercado de trabalho na cidade, que vem cobrando crescentes qualificações.

No entanto, a diferenciação entre as distintas ZHs não se repete quando se observa a distribuição da inserção dos jovens no mercado formal de trabalho, visto que 52,2\% daqueles que trabalham não têm carteira de trabalho assinada (Tabela 6): na ZH1 51,5\% e na ZH5 51,3\%. Este dado aponta para uma precarização do mercado de trabalho no conjunto da cidade.

Tabela 5: Inserção no mercado de trabalho por Zona Homogênea - Mapa da Juventude da Cidade de São Paulo, 2003

\begin{tabular}{lcccccc}
\hline & $\begin{array}{c}\mathrm{ZH} 1 \\
\%\end{array}$ & $\begin{array}{c}\mathrm{ZH} 2 \\
\%\end{array}$ & $\begin{array}{c}\mathrm{ZH} 3 \\
\%\end{array}$ & $\begin{array}{c}\mathrm{ZH} 4 \\
\%\end{array}$ & $\begin{array}{c}\text { ZH5 } \\
\%\end{array}$ & $\begin{array}{c}\text { Total } \\
\%\end{array}$ \\
\hline Não & 56,4 & 64,6 & 64,7 & 70,8 & 68,1 & 66,8 \\
Sim & 43,6 & 35,4 & 35,3 & 29,2 & 31,9 & 33,2 \\
\hline Total & 100,0 & 100,0 & 100,0 & 100,0 & 100,0 & 100,0 \\
\hline
\end{tabular}

Tabela 6: Inserção no mercado de trabalho formal por Zona Homogênea - Mapa da Juventude da Cidade de São Paulo, 2003

\begin{tabular}{lcccccc}
\hline & $\begin{array}{c}\mathrm{ZH} 1 \\
\%\end{array}$ & $\begin{array}{c}\mathrm{ZH} 2 \\
\%\end{array}$ & $\begin{array}{c}\mathrm{ZH} 3 \\
\%\end{array}$ & $\begin{array}{c}\mathrm{ZH} 4 \\
\%\end{array}$ & $\begin{array}{c}\mathrm{ZH} 5 \\
\%\end{array}$ & $\begin{array}{c}\text { Total } \\
\%\end{array}$ \\
\hline Sim & 41,2 & 43,5 & 44,8 & 39,2 & 45,6 & 43,3 \\
Não & 51,5 & 51,1 & 53,6 & 52,6 & 51,3 & 52,2 \\
Ignorado & 7,3 & 5,4 & 1,5 & 8,2 & 3,1 & 4,5 \\
\hline Total & 100,0 & 100,0 & 100,0 & 100,0 & 100,0 & 100,0 \\
\hline
\end{tabular}

Outra dimensão do perfil de exclusão/inclusão desses jovens refere-se à sua inserção no mundo digital. Se esta questão é importante para o conjunto do país, ela se reveste de particular significado na metrópole paulista, pois é aqui que a tecnologia da informação adquire maior peso, influenciando fortemente o mercado de trabalho (Bousquat, 2000; Silveira, 2003). Constatou-se que apenas $38,2 \%$ dos jovens utilizam a Internet, com acentuada diferença entre as distintas ZHs: $72,4 \%$ dos jovens da ZH1 acessam a Internet, em contraposição a apenas 24,1\% deles na ZH5 (Gráfico 1). 


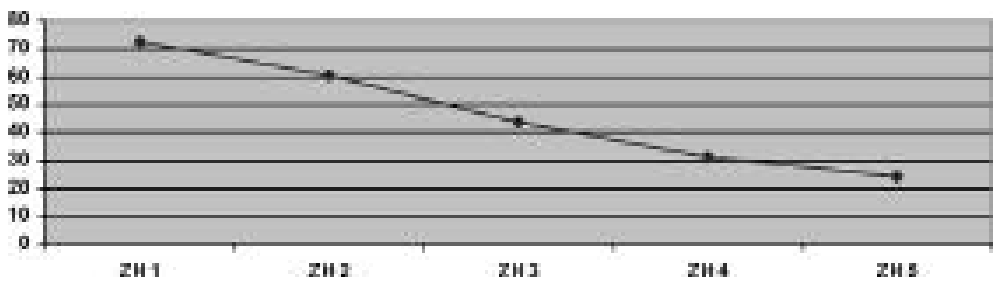

Gráfico 1: Percentual de utilização da Internet por Zona Homogênea Mapa da Juventude da Cidade de São Paulo, 2003

Dentre as várias atividades de lazer, ganham destaque aqui as preferências musicais dos jovens. Mas, se estas os tornam conhecidos como "funkeiros", rappers, "pagodeiros", "rockeiros" e por tantas outras denominações, são as características específicas a cada um desses estilos que revelam algo mais sobre o seu modo de viver (Carmo, 2001).

As preferências de estilos musicais mencionados pelos jovens podem ser observadas na Tabela 7, chamando a atenção o fato de nas ZH1 e $\mathrm{ZH} 2$ prevalecerem o rock, a MPB e o axé, enquanto nas demais ZHs prevalecem o samba, o pagode e o axé seguido de perto pelo rock. Na ZH5 ainda se observa uma escolha equilibrada entre aqueles que preferem o rock $(42,4 \%)$ e o rap (42,9\%), enquanto na $\mathrm{ZH} 1$ a maioria dos jovens prefere o rock (63,5\%), seguido da MPB (44,2\%). Quanto aos estilos musicais geralmente associados aos jovens - o funk e o techno -, eles apresentam tendência inversa. No caso do funk, a preferência é menor na ZH1 (10,9\%) e cresce gradativamente em direção à ZH5 (27,6\%); a música techno, ao contrário, tem preferência maior na ZH1 (35,9\%) se comparada à ZH5 (19,5\%).

As preferências musicais desses jovens por $\mathrm{ZH}$ corroboram o fato de que determinadas práticas de lazer, por estarem relacionadas a fatores socioeconômicos e à oferta de serviços - como bares e boates -, se distribuem desigualmente pela cidade, ao que se associam traços culturais, como parece ser evidente no caso da menção ao funk apontada por $32,5 \%$ dos jovens negros, e somente por $22,8 \%$ dos jovens brancos na ZH5, com maior índice de exclusão social.

O conjunto dos dados sobre os perfis dos jovens paulistanos revela distintos padrões de inserção na metrópole paulista, permitindo que se componha um caleidoscópio de situações de inclusão e exclusão social que comungam, no entanto, uma realidade socioeconômica segregadora no uso desse espaço urbano. Segregação esta que não obedece a um padrão homogêneo nem tampouco logra subjugar os jovens à conformidade da 
Tabela 7: Estilos musicais preferidos por Zona Homogênea - Mapa da Juventude da Cidade de São Paulo, 2003

\begin{tabular}{llllll}
\hline Estilo Musical & ZH1 & ZH2 & ZH3 & ZH4 & ZH5 \\
\hline Samba & 30,1 & 31,8 & 57,5 & 55,3 & 49,7 \\
Rock & 63,5 & 51,7 & 52,5 & 44,4 & 42,4 \\
Pagode & 19,2 & 27,6 & 53,8 & 51,2 & 47,2 \\
Axé & 17,3 & 35,6 & 46,4 & 49,3 & 45,2 \\
Reggae & 35,9 & 33,3 & 50,2 & 45,4 & 39,2 \\
Rap & 21,2 & 23,0 & 46,4 & 43,7 & 42,9 \\
Forró & 23,1 & 31,0 & 47,8 & 42,2 & 36,8 \\
MPB & 44,2 & 31,4 & 42,4 & 37,5 & 28,8 \\
Pop & 37,2 & 32,2 & 35,5 & 31,9 & 28,0 \\
Funk & 10,9 & 13,4 & 30,5 & 28,3 & 27,6 \\
Techno & 35,9 & 26,1 & 28,5 & 26,8 & 19,5 \\
\hline
\end{tabular}

indiferença. Nesse sentido, os dados obtidos através da metodologia aqui exposta e que resultaram no Mapa da Juventude da Cidade de São Paulo permitem atestar sua adequação ao objetivo de se contemplar a diversidade da conformação socioespacial urbana.

AYLENE BOUSQUAT é médica, professora do Programa de Pós-graduação em Saúde Coletiva da Universidade Católica de Santos e pesquisadora do Cedec. AMÉLIACOHN é socióloga, professora do Departamento de Medicina Preventiva da Faculdade de Medicina da USP e pesquisadora do Cedec.

\section{REFERÊNCIAS BIBLIOGRÁFICAS}

BÓGUS, L. e WANDERLEY, L. A luta pela cidade de São Paulo. São Paulo: Cortez, 1992.

BONDUKI, N. e ROLNIK, R. "Periferia da Grande São Paulo: reprodução do espaço comoexpediente da reprodução da força de trabalho". In: MARICATO, E. (org.). A produção capitalista da casa e da cidade no Brasil industrial. São Paulo: AlfaÔmega, 1982

BORJA, J. e CASTELLS, M. Local y global. La gestión de las ciudades en la era de lainformación. Madrid: Taurus, 1998

BOUSQUAT, A. Para a incorporação do espaço no estudo da saúde. São Paulo:Departamento de Medicina Preventiva da FMUSP, 2000 (Tese de doutorado).

BRANT, V. C. (coord.). São Paulo, trabalhar e viver. São Paulo: Comissão Justiça e Paz de São Paulo/Editora Brasiliense, 1989.

CARMO, Paulo Sérgio (coord.). As caras da juventude. São Paulo: Fundação Konrad Adenauer, 2001, p. 10 (Cadernos Adenauer II, nº 6).

DIAS, A. e GOMES, W. "Conversas, em família, sobre sexualidade e gravidez na adolescên- 
cia: percepção das jovens gestantes". Psicol. Reflex. Crit., vol. 13, n¹, 2000, pp. 109-125.

FAINSTEIN, S.; GORDON, I. e HARLOE, M. Divided cities: New York and London in the contemporary world. London: Blackwell, 1992, pp. 176-216.

GUIMARÃES, A. S. A. "Como trabalhar com 'raça'em sociologia". Educação e Pesquisa, vol. $29, \mathrm{n}^{\circ} 1,2003$, pp. 93-107.

HENRIQUES, M. H.; SILVA, N.; SINGH, S.; WULF, D. Adolescentes de hoje, pais do ama nhã: Brasil. Nova York: Alan Gutmacher Institute, 1989.

JACOBI, P. Movimentos sociais e políticas públicas. São Paulo: Cortez, 1989.

KOWARICK, L. A espoliação urbana. São Paulo: Paz e Terra, 1979.

LEFÈBVRE, H. O Direito à Cidade. Documentos, São Paulo, 1966 The survival of capitalism. London: Allison and Busby, 1976

La revolución urbana. Alianza: Madrid, 1983

A vida cotidiana no mundo moderno. São Paulo: Ática, 1991.

The production of space. Oxford: Blackwell, 1995.

LENCIONI, S. "Mudanças na metrópole de São Paulo (Brasil) e transformações industriais". Revista do Departamento de Geografia, $\mathrm{n}^{\circ}$ 12, 1998, pp. 27-42.

LOGAN, J. "Still a global city: the racial and ethnic segmentation of New York". In:

MARCUSE, P. e KEMPEN, R. Globalizing cities: a new spatial order?. London: Blackwell, 2000, pp. 158-185.

MARCUSE, P. "Space and race in the post-fordist city: the outcast guetto and advanced homelessness in the United States today". In: MINGIONE, E. Urban poverty and underclass. London: Blackwell, 1996, pp. 176-216.

MARQUES, E. e BICHIR, R. "Estado e espaço urbano: revisitando criticamente as expl cações sobre as políticas urbanas". Revista de Sociologia e Política, Curitiba, jun. 2001, pp. 9-29.

MELLO, Karla Reis Cardoso. Transporte urbano de passageiros: as contradições do poder público. São Paulo: Departamento de Geografia da FFLCH-USP, 1998 (Tese de doutorado).

OLIVEIRA, M. W. "Gravidez na adolescência: Dimensões do problema". Cad. CEDES, vol. 19, n 45 , jul. 1998, pp. 48-70.

PETRUCCELLI, J. L. "Raça, etnicidade e origem nos Censos de EUA, França, Canadá e GrãBretanha". Estudos Afro-Asiáticos, vol. 24, n 3, 2002, pp. 533-561.

RIBEIRO, L. e LAGO, L. "Crise e mudança nas metrópoles brasileiras: a periferização em questão". In: LEAL, Maria do Carmo et alii (orgs.). Saúde, ambiente e desen volvimento. Rio de Janeiro: Hucitec, 1992.

SANTOS, C. Processo de crescimento e ocupação da periferia. Rio de Janeiro: IBAM/CPU, 1982.

SANTOS, M. O espaço do cidadão. São Paulo: Nobel, 1993a.

. Por uma economia política da cidade - o caso de São Paulo. São Paulo: Hucitec/EDUC, 1994.

SOJA, EDWARD. Geografia pós-moderna: a reafirmação do espaço na teoria social. Rio de Janeiro: Zahar, 1989.

TORRES, H.; MARQUES, E.; FERREIRA, M. e BITAR, S. "Pobreza e espaço: padrões de segregação em São Paulo”. Estudos Avançados, vol. 17, n 47, 2003. 